\title{
PEMANFAATAN IKAN ROA DALAM PEMBUATAN ABON DENGAN BERBAGAI VARIAN RASA DI SMKN 1 BATUDAA KABUPATEN GORONTALO
}

\section{Utilization of fish Roa In Making Abon With Various Flavors In Batudaa Vocational Scholl, Gorontalo District}

\author{
Adnan Engelen"), Syaiful Umela ${ }^{2)}$, Desi Arisanti' ${ }^{3)}$, Abdul Azis Hasan ${ }^{4)}$, Rosdiani Azis ${ }^{5)}$, \\ Ingka Rizkyani Akolo6), Ika Okhtora Angelia ${ }^{7)}$ \\ 1, 2, 3, 4, 5, 6, 7, Staf Pengajar Program Studi Teknologi Hasil Pertanian, Politeknik Gorontalo \\ Jl. Muchlis Rahim Desa Panggulo, Kec. Botupingge, Kab. Bone Bolango, Prov. Gorontalo \\ Email : adnanengelen@poligon.ac.id
}

\begin{abstract}
ABSTRAK
Ikan roa merupakan ikan khas yang berasal dari Perairan Sulawesi. Di Gorontalo ikan roa ini mengalami pengasapan yang dikenal sebagai ikan Sagela. Lokasi pengabdian masyarakat oleh tim dosen Politeknik Gorontalo adalah SMKN 1 Batudaa Kabupaten Gorontalo memiliki jurusan perikanan. Belum adanya inovasi pangan dari turunan produk ikan roa asap ini menjadikan ide dari tim dosen Teknologi Hasil Pertanian Politeknik Gorontalo untuk mengolahnya menjadi abon. SMKN 1 Batudaa merupakan sekolah kejuruan yang mempunyai tujuan untuk menyiapkan tenaga kerja yang terampil di tingkat menengah yang siap berwirausaha. Metode pelaksanan program, tidak hanya materi dalam bentuk audio visual yang diberikan namun peserta juga diberikan manual/panduan bagaimana tahapan dalam pembuatan abon ikan roa asap. Hasil setelah kegiatan ini didapatkan bahwa guru dan siswa SMK dari sekolah tersebut memperoleh keterampilan dalam pengolahan pangan khususnya ikan roa asap menjadi abon. Selain itu dapat dijadikan peluang berwirausaha bagi siswa dan sebagai inovasi pembuatan abon ikan Roa ini memperkaya rasa dan nilai gizi yang dikandungnya menjadi lebih bervariasi.
\end{abstract}

\section{Kata Kunci: SMKN 1 Batudaa; ikan roa; ikan sagela}

\begin{abstract}
Roa fish are typical fish originating from Sulawesi. In Gorontalo, this roa fish requires fumigation known as Sagela fish. The location of community service by the Gorontalo Polytechnic lecturer team was SMKN 1 Batudaa District Gorontalo having a fisheries department. Not yet presenting food from derivatives of roa fish products as soon as possible made an idea from the lecturer team of Gorontalo Polytechnic Technology for processing it into shredded meat. High School of vocation 1 Batudaa was a vocational school that had the aim of preparing workers who were ready at the middle level who are ready for entrepreneurship. The method of implementing the program, not only the material in the form of audio-visual provided but also provided a manual/guide on how to complete the making of shredded roa fish. The results after this activity
\end{abstract}


were obtained by teachers and vocational students from this school required skills in processing roa fish food immediately to be shredded. Also, opportunities for entrepreneurship could be made for students and also the makers of Roa abon fish to enrich their taste and the nutritional value they contain became more varied.

Keywords: SMKN 1 Batudaa; roa fish; sagela fish

\section{PENDAHULUAN}

Ikan Roa merupakan ikan khas yang berasal dari Perairan Sulawesi, di Gorontalo ikan roa menjadi habitat untuk ikan ini hidup. Ikan Roa yang telah dilakukan pengasapan bagi masyarakat Gorontalo lebih dikenal dengan ikan sagela atau ikan Tore (Harjan dkk, 2018). Pada umumnya masyarakat Gorontalo mengolah ikan sagela ini hanya sebagai campuran dalam sambal atau tambahan dalam sayur santan. Sehingga menimbulkan kejenuhan dalam mengkonsumsi ikan tersebut. Selain itu masyarakat pariwisata yang datang ke Gorontalo tidak bisa membawa oleh-oleh hasil olahan dari ikan roa asap ini.

Belum adanya inovasi pangan dari turunan produk ikan roa asap ini menjadikan ide dari tim dosen Teknologi Hasil Pertanian Politeknik Gorontalo untuk mengolahnya menjadi abon. Produk Abon ikan roa asap ini sudah pernah diikutkan dalam lomba Teknologi Tepat Guna (TTG) tingkat Kabupaten Bone Bolango pada tahun 2017 dan mendapat respon positif dari pemerintah Daerah Bone Bolango dan Disperindag Provinsi untuk dikembangkan oleh Politeknik Gorontalo.Dalam pengembangan produk abon ikan roa asap ini akan dikembangkan abon ikan roa asap dengan berbagai variasi rasa dana roma yang khas (Patty dkk, 2015).

Pada pengabdian kali ini daerah yang dipilih sebagai pusat pelatihan adalah SMKN 1 Batudaa. Sekolah ini dipilih dikarenakan ada jurusan perikanan untuk konsentrasi siswanya. Dan yang menjadi target sebagai peserta adalah guru dan siswa dari SMK tersebut. Sekolah menengah kejuruan (SMK) merupakan salah satu pendidikan yang mempunyai tujuan untuk menyiapkan tenaga kerja yang terampil di tingkat menengah yang siap. Sehingga diharapkan ilmu yang diterima dapat dikembangkan dalam bentuk wirausaha. Selain itu juga kegiatan pelatihan ini dapat menunjang peningkatan kompetansi siswa sesuai dengan bidang minat dan kemampuannya dalam pengolahan produk.

\section{Permasalahan Mitra}

Siswa SMK merupakan salah satu SDM yang bisa diandalkan untuk bisa bekerja pada sektor-sektor tertentu. Sekarang banyak kita temui lulusan SMK atau siswa SMK sudah bisa menciptakan sebuah produk seperti pembuatan mobil berbahan biofuel. Namun keterampilan tersebut belum semua merata dimiliki oleh siswa SMK, sehingga diperlukan adanya inovasi dari kampus sebagai salah satu penghasil SDM unggul dalam hal transfer ilmu atau inovasi bagi siswa-siswa SMK agar bisa meningkatkan keterampilan dan ilmu pengetahuannya. Politeknik Gorontalo merupakan kampus yang siap menampung lulusan siswa SMK, dikarenakan lulusan dari kampus tersebut akan menghasilkan lulusan yang mempunyai semangat dalam berwirausaha. Oleh karenanya, pengabdian ini merupakan salah satu jalan untuk mencerdasakan sumber daya manusia.

\section{SOLUSI DAN TARGET LUARAN Solusi Permasalahan}

Salah satu solusi dari permasalahan yang terjadi yaitu belum dikembangkannya produk diversifikasi dari produk turunan ikan roa asap Dengan adanya pelatihan tersebut guru dan siswa akan mendapatkan materi baik secara teori maupun praktek secara langsung. 
Secara terperinci tujuan pelaksanaan kegiatan pelatihan ini adalah sebagai berikut:

1. Meningkatkan nilai ekonomis dari ikan roa asap menjadi produk yang lebih bernilai dari sebelumnya.

2. Abon ikan roa asap dengan berbagai varian rasa kedepannya diharapkan dapat menjadi salah satu makanan khas dari Provinsi Gorontalo yang dapat dikembangkan menjadi oleholeh bagi parawisatawan.

\section{Luaran dan Target Capaian}

Luaran yang diharapkan dari kegiatan ini adalah :

1. Menyiapkan tenaga kerja yang terampil tingkat menengah yang siap pakai yang dibutuhkan oleh dunia kerja.

2. Menambah pengetahuan guru dan siswa tentang produk diversifikasi dari ikan roa asap.

\section{METODE PELAKSANAAN}

Saat pelaksanan program, tidak hanya materi dalam bentuk audio visual yang akan diberikan namun peserta juga akan diberikan manual/panduan bagaimana tahapan dalam pembuatan abon ikan roa asap. Diharapkan setelah kegiatan ini, guru dan siswa SMK dari sekolah tersebut memperoleh keterampilan dalam pengolahan pangan khususnya ikan roa asap menjadi abon. Selain itu dapat dijadikan peluang berwirausaha bagi siswa.

Bagi Politeknik Gorontalo keuntungan yang diharapakn dari pelatihan ini adalah terbentuknya kerjasama antara kampus dan sekolah. Sehingga bisa berdampak bagi ketertarikan siswa untuk melanjutkan kuliah di kampus Politeknik Gorontalo. Selain itu juga pelatihan ini juga sebagai salah satu sarana untuk mempromosikan politeknik Gorontalo dengan segala fasilitas penunjang dan prestasi yang telah diraih baik oleh mahasiswa atau dosen.

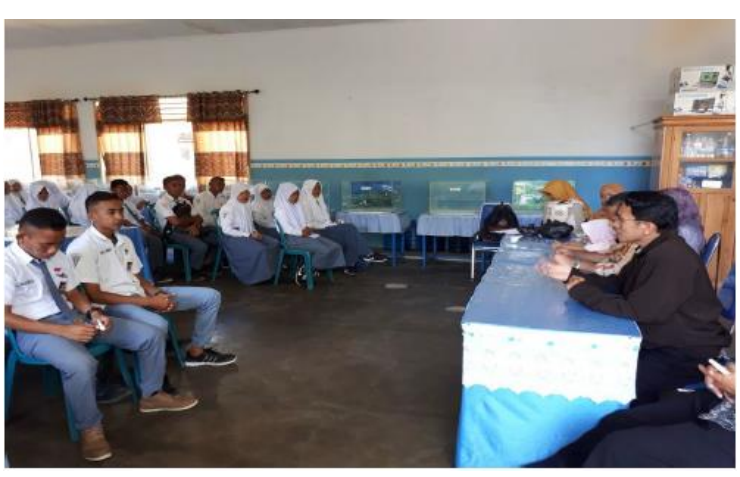

Pengabdian Masyarakat ini akan dilaksanakan SMKN 1 Batudaa Kabupaten Gorontalo pada bulan Mei-Juni 2017.

\section{Alat dan Bahan yang digunakan dalam pelatihan}

\section{Alat}

Alat-alat yang digunakan dalam pelatihan ini adalah: pisau, loyang, kompor gas, wajan, pengaduk, timbangan analitik.

\section{Bahan}

Bahan utama yang digunakan dalam pelatihan yaitu: ikan sagela.

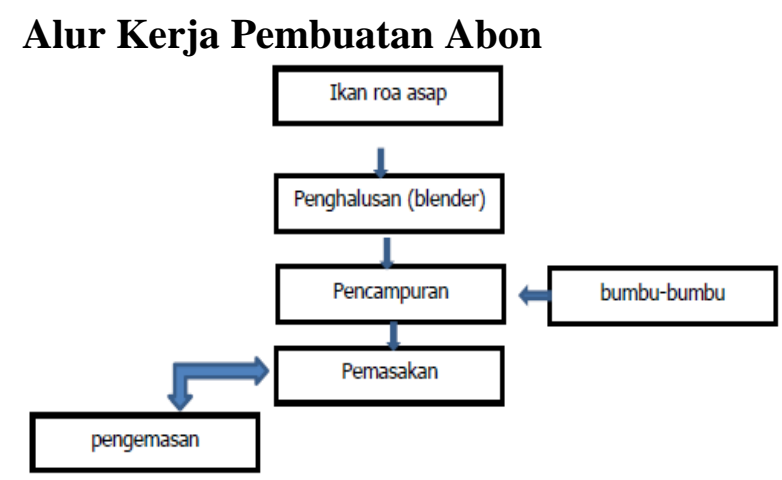

Gambar 1. Alur Kerja Pembuatan Abon

\section{HASIL DAN PEMBAHASAN}

Program Kemitraan Masyarakat (PKM) yang dilaksanakan di SMKN 1 Batudaa Kabupaten Gorontalo pelaksanaanya terjadwal, dan berjalan sesuai rencana. Pada tahap persiapan dilaksanakan observasi dan permohonan izin ke sekolah yang menjadi tujuan (SMKN 1 Batudaa) guna mendapatkan izin untuk melaksanakan kegiatan pelatihan, sekaligus 
menginformasikan target jumlah peserta dan kriteria peserta yang akan diikutkan dalam pelaksanaan kegiatan. Setelah izin diberikan ketua pelaksana menyusun jadwal pelaksanaan kegiatan sesuai dengan hasil kesepakatan bersama dalam rapat koordinasi pendahuluan dengan tim pelaksana yang terdiri dari 6 orang dosen dari Program Studi Teknologi Hasil Pertanian.

Kegiatan pelatihan ini bertemakan bagaimana membuat produk turunan dari ikan Roa atau bila didaerah gorontalo dikenal dengan ikan sagela. Produk yang diajarkan pada pelatihan tersebut adalah membuat abon dari ikan Roa. Pelatihan diberikan berupa pemberian keterampilan kepada siswa dan guru dari jurusan agribisnis perikanan di SMKN 1 Batudaa. Seperti yang telah diuraikan dalam latar belakang pelatihan ini, ikan Roa merupakan ikan asap yang cukup digemari oleh masyarakat setempat dan mudah dijumpai di pasar maupun warung-warung kecil. Namun perlu inovasi untuk membuat produk turunan dari ikan ini agar mudah dikonsumsi dalam bentuk instan dan mudah dibawa apabila akan dijadikan oleh-oleh buah tangan. Sehingga timbulah ide dari tim pelaksana untuk dijadikan abon yang harapannya akan digemari oleh semua kalangan.

Adapun tahapan pelaksanaan pelatihan meliputi: 1) tahap persiapan, yaitu survey tempat dilaksanakannya pelatihan, jumlah peserta, menyusun bahan dan alat yang akan dibawa pada saat pelatihan, menyiapakan materi praktik pembuatan abon ikan roa yang akan diberikan pada pelatihan. 2) tahap pelaksanaan, yaitu kegiatan dilaksanakan pada tanggal Agustus 2017 pukul 10.00 WITA di Ruang praktik jurusan agribisnis perikanan. Adapun tahapan pelatihan meliputi: 1) pelatihan menitik beratkan pada kemampuan kognitif peserta berupa pembekalan materi tekait dengan ikan Roa dan kandungan gizi yang terdapat pada ikan tersebut, dan juga pengenalan alat dan bahan penunjang dalam pembuatan abon,dan 2) pelatihan pembuatan abon abon ikan roa.

Pada pelatihan pertama, materi pelatihan diberikan kepada setiap peserta berupa uraian atau langkah-langkah dalam pembuatan abon ikan roa dengan berbagai varian rasa yaitu rasa original dan rasa pedas, dan pemberian resep dasar dari abon ikan Roa. Pelatihan dimulai dengan memperkenalkan Politeknik Gorontalo dan Program Studi Teknologi Hasil Pertanian kemudian dilanjutkan dengan demontrasi pembuatan abon ikan Roa.

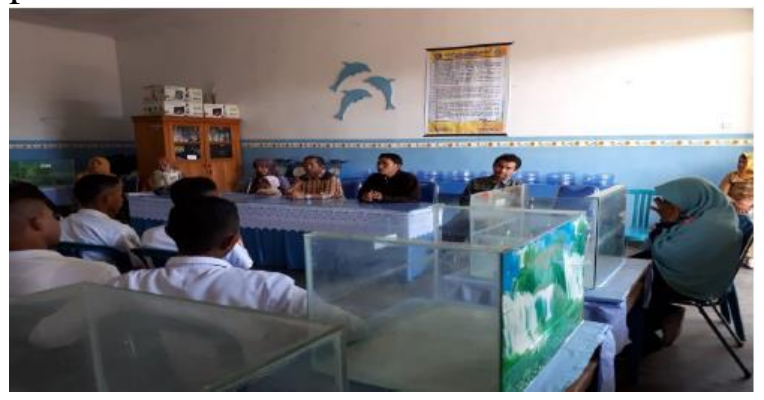

Arahan dan tanya jawab berlangsung selama kegiatan. Tim pelaksanana menjelaskan langkah-langkah pembuatannya sambil mendemontrasikan prosen pembuatan abon ikan roa. Pelatihan berlangsung dari pukul 10.00-11.30 WITA.

Adapun Tahap Pengolahan Ikan Roa asap menjadi abon adalah sesuai tahapantahapan berikut ini :

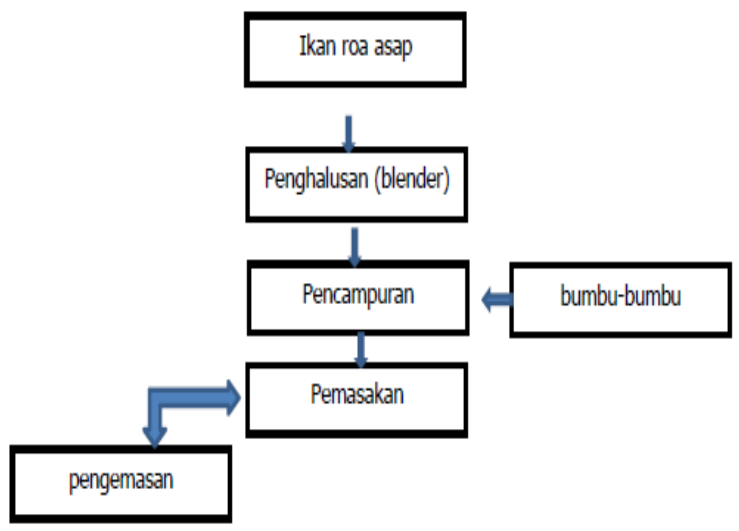

Gambar 2. Tahapan Pengolahan Ikan Roa

Evaluasi pada tahap pertama dengan indikator dan rancangan evaluasi diperoleh sebagai berikut: 
1) Jumlah peserta yang hadir sebanyak 30 orang yang terdiri dari siswa dan guru yang ditargetkan $100 \%$.

2) Keantusiasan peserta pelatihan sangat jelas dimana seluruh peserta terlibat aktif selama kegiatan berlangsung.

3) Evaluasi terhadap produk sesuai dengan indikator dan tolak ukur produk yang dihasilkan memiliki rasa guruh dan pedas.

4) Evaluasi terhadap tingkat kesukaan peserta hampir semua peserta menyukai produk yang dihasilkan.

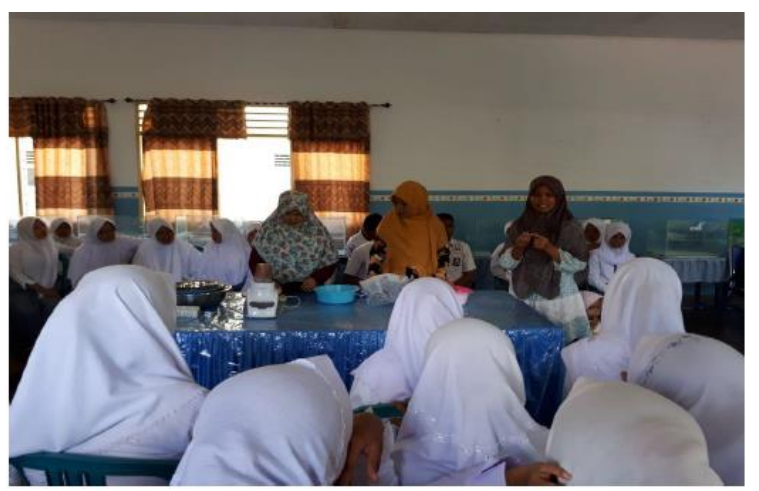

Evaluasi kegiatan pelatihan secara umum berjalan dengan baik dan memuaskan peserta maupun tim pelaksana. Peserta berharap ditahun-tahun kemudian dapat diberikan kesempatan mendapatkan pelatihan sejenis. Sumber pangan lokal yang beragam jika diolah dengan baik akan membirikan prospek baik ke depan.

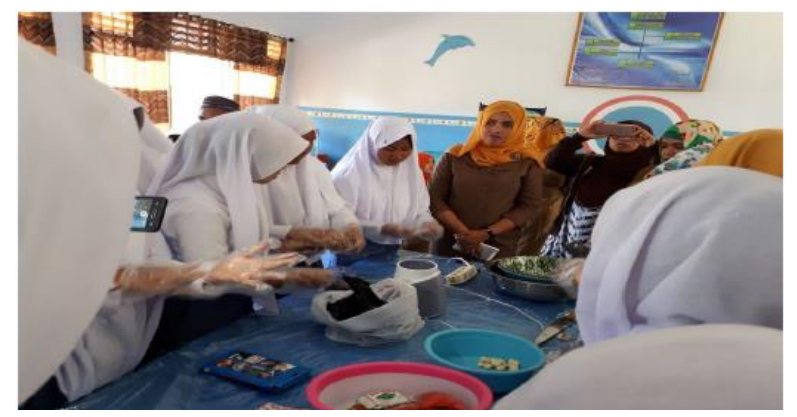

Pada kegiatan pelatihan ini peserta diharapkan dapat mengembangkannya dalam bentuk berwirausaha atau mengembangkannya dalam industri rumah tangga.

\section{KESIMPULAN DAN SARAN}

\section{A. Kesimpulan}

1. Secara keseluruhan kegiatan pengembangan produk abon ikan Roa ini berjalan dengan baik dan lancar. Dampak pelatihan memberikan bekal keterampilan abon ikan Roa yang disukai dan memiliki peluang untuk dikembangkan sebagai lahan bisnis.

2. Dengan dikuasainya ketermapilan pembuatan abon ikan Roa oleh peserta berdampak juga pada keterampilan yang diperoleh. Inovasi pembuatan abon ikan Roa ini akan memperkaya rasa dan nilai gizi yang dikandungnya menjadi lebih bervariasi.

\section{B. Saran}

1. Kepada peserta pelatihan disarankan untuk terus melatihkan pengetahuan dan keterampilan yang telah dimiliki agar mendapatkan hasil yang lebih baik dan lebih bervariasi.

2. Politeknik Gorontalo khususnya Program Studi Teknologi Hasil Pertanian agar terus menciptakan inovasi produk pangan yang dapat diterapkan kepada masyarakat.

\section{DAFTAR PUSTAKA}

Harjan I, Rasulu H, Saleh ERM. 2018. Penentuan umur simpan ikan roa asap (ikan julung julung asap) (Hemirhampus Sp) menggunakan metode ASLT (Accelerated Shel life testing) dengan pendekatan Arrhenius. TECHNO: Vol 07 (1) Mei 2018.

Patty NC, Dotulong V, Suwetja IK. 2015. Mutu ikan roa (Hemirhamphus sp) asap yang ada di pasar tradisional di Kota Menado yang disimpan pada suhu ruang. Jurnal Media Teknologi Hasil Perikanan: Vol 3 (2) agustus 2015 